Article

\title{
Multi-Annual Kinematics of an Active Rock Glacier Quantified from Very High-Resolution DEMs: An Application-Case in the French Alps
}

\author{
Xavier Bodin 1,* (D), Emmanuel Thibert ${ }^{2}$, Olivier Sanchez ${ }^{3}$, Antoine Rabatel ${ }^{3}$ \\ and Stéphane Jaillet ${ }^{1}$ \\ 1 Université Grenoble Alpes, CNRS, Université Savoie Mont-Blanc, Laboratoire Environnements, \\ Dynamiques et Territoire de Montagne (EDYTEM, UMR 5204), 73000 Chambéry, France; \\ stephane.jaillet@univ-smb.fr \\ 2 Université Grenoble Alpes, Irstea, UR ETGR, 2 rue de la Papeterie-BP 76, 38402 St-Martin-d'Hères, France; \\ emmanuel.thibert@irstea.fr \\ 3 Institut des Géosciences de l'Environnement (IGE, UMR 5001), Université Grenoble Alpes, CNRS, IRD, \\ G-INP, F-38000 Grenoble, France; oliviersanchez64@gmail.com (O.S.); \\ antoine.rabatel@univ-grenoble-alpes.fr (A.R.) \\ * Correspondence: xavier.bodin@univ-smb.fr; Tel.: +33-4-797-594-43
}

Received: 11 January 2018; Accepted: 29 March 2018; Published: 3 April 2018

check for updates

\begin{abstract}
Rock glaciers result from the long-term creeping of ice-rich permafrost along mountain slopes. Under warming conditions, deformation is expected to increase, and potential destabilization of those landforms may lead to hazardous phenomena. Monitoring the kinematics of rock glaciers at fine spatial resolution is required to better understand at which rate, where and how they deform. We present here the results of several years of in situ surveys carried out between 2005 and 2015 on the Laurichard rock glacier, an active rock glacier located in the French Alps. Repeated terrestrial laser-scanning (TLS) together with aerial laser-scanning (ALS) and structure-from-motion-multi-view-stereophotogrammetry (SFM-MVS) were used to accurately quantify surface displacement of the Laurichard rock glacier at interannual and pluri-annual scales. Six very high-resolution digital elevation models (DEMs, pixel size $<50 \mathrm{~cm}$ ) of the rock glacier surface were generated, and their respective quality was assessed. The relative horizontal position accuracy $(\mathrm{XY})$ of the individual DEMs is in general less than $2 \mathrm{~cm}$ with a co-registration error on stable areas ranging from $20-50 \mathrm{~cm}$. The vertical accuracy is around $20 \mathrm{~cm}$. The direction and amplitude of surface displacements computed between DEMs are very consistent with independent geodetic field measurements (e.g., DGPS). Using these datasets, local patterns of the Laurichard rock glacier kinematics were quantified, pointing out specific internal (rheological) and external (bed topography) controls. The evolution of the surface velocity shows few changes on the rock glacier's snout for the first years of the observed period, followed by a major acceleration between 2012 and 2015 affecting the upper part of the tongue and the snout.
\end{abstract}

Keywords: rock glacier deformation; very high-resolution DEM; surface displacement; image correlation; TLS; ALS; SFM-MVS

\section{Introduction}

Because of their abundance in many poorly-glacierized mountain regions of the world [1], rock glaciers are key features to understand the response of the high altitude cryosphere to climate change [2]. Rock glaciers typically flow downslope at relatively low and steady rates, exhibiting surface velocity typically ranging from a few $\mathrm{cm}$ to $2 \mathrm{~m}$ per year [1]. In the Alps, synchronous inter-annual 
fluctuations of surface velocities have been observed on many rock glaciers, suggesting a control of the ground thermal state on the deformation rate of the permafrost $[3,4]$. Some cases of rock glaciers' destabilization were also observed in various mountain chains, such as in the Alps $[5,6]$ or in the Andes [7], becoming a potential source of hazards [8]. These temporal changes in rock glaciers' deformation patterns pointed out various mechanical processes involved in their behavior [9]. In this context, developing a sound knowledge of the spatial and temporal variabilities of the surface velocity of rock glaciers, as a proxy of their deformation and an indicator of their climatic controls, is needed. It is indeed a prerequisite for future efforts aiming at analyzing their physico-mechanical behavior and the driving factors, among which the climate probably plays a substantial role [3,10-12].

Because investigating the internal deformation of rock glaciers is very costly and limited to a single one-dimensional vertical profile along boreholes, the surface displacement is the most easily "accessible" variable for characterizing rock glacier dynamics and deformation patterns. The kinematics of the topographical surface integrates the overall vertical profile of deformation, including creeping and shearing, and their changes in space and in time are valuable information for understanding the factors that rule the deformation. Surface kinematics of rock glaciers are generally measured and monitored either remotely, with terrestrial, aerial or spatial vectors (see, e.g., [13,14]), or with in situ measurements, by geodetic methods (total station, differential GPS; see, e.g., [15]). The first set of approaches has the advantage of a wide spatial coverage, using imagery with a pixel resolution of a few decimeters to a few meters (ground sample distance (GSD)). It is nevertheless limited by the temporal availability of datasets, typically several years to decades. In the second set of methods, the surface topography can be acquired more frequently (as often as an operator can go out in the field to carry out surveys), but it results in poorly representative data in spatial terms, because it consists of punctual information (generally a marked block at the surface that can be tracked from year-to-year). Other methods for continuous measurements and monitoring of ground surface changes, like continuous L1-GPS [16] or fixed camera [12], are allowed by very recent technological developments, but remain up to now costly and not so easy to implement.

Terrestrial and airborne laser scanning (TLS, ALS) and terrestrial photogrammetry (or structurefrom-motion/multi-views stereophotogrammetry (SFM-MVS)) constitute intermediary approaches. Because of their relative simplicity in handling, these approaches easily allow one to generate (very) high-resolution digital elevation models (DEM). In addition, their repetitivity can be annual or even at smaller time intervals, mostly depending on the terrain characteristics and the range of surface velocities. So far, these methods have rarely been used for rock glacier studies [17-20], and no investigations have yet addressed the potential of those methods for long-term monitoring of the surface kinematics.

\section{Aims and Objectives}

In order to investigate the multi-temporal kinematics of rock glaciers and, ultimately, to better understand their climatic controls, we took advantage of an easily-accessible site with one of the longest time-series of ground-truth data (since the early 1980s; see [21]). On this active rock glacier located in the French Alps, we carried out several TLS, ALS and SFM-MVS surveys. The objectives of the present study are to describe and evaluate very high resolution DEMs of the studied rock glacier, to determine its surface velocity fields at various temporal scales, to evaluate the spatial characteristics of the rock glacier kinematics and to discuss the geomorphological significance of the results.

After presenting the study site (Section 3) and the methods used (Section 4), we describe the datasets (Section 5) and their analysis (Section 6). These last two sections include: (i) an evaluation of the data quality by estimating the vertical and horizontal errors; (ii) the determination of the surface displacement fields at various temporal scales; and (iii) the analysis of the surface displacement changes through time and space. Finally, the significance of those results in terms of possible causes of the spatio-temporal changes of rock glacier surface displacements is discussed (Section 7). 


\section{Study Site}

\subsection{Main Characteristics}

The Laurichard active rock glacier is located in a transitional climate zone between the northern French Alps, affected by an oceanic regime, and the southern French Alps, mostly subjected to the Mediterranean influence. Using regionalization results from the SAFRANmodel provided by [22], the mean zero-isotherm altitude (ZIA) in the Laurichard area over the 1958-2002 period can be estimated to be around $2450 \mathrm{~m}$ asl; whereas the mean annual sum of precipitation is around $1000 \mathrm{~mm}$ at $1800 \mathrm{~m}$ asl, and the mean snow cover duration is about 220 days per year [23].

The debris that constitutes the rock glacier is predominantly of granitic lithology, falling down from a densely-fractured $600 \mathrm{~m}$-high rock wall. This gravitational activity feeds the rock glacier with relatively large boulders, which constitute an open-work debris accumulation that largely covers the slopes around.

The Laurichard rock glacier has a rather simple morphology, with an $800 \mathrm{~m}$-long and 100-200 m-wide tongue, flowing down between $2650 \mathrm{~m}$ a.s.l. at the rooting zone (foot of the rock wall) and $2450 \mathrm{~m}$ a.s.l. at the snout. The activity of the rock glacier is evidenced by: (i) the presence of transversal ridges and furrows; (ii) a steep and unstable latero-frontal talus; and (iii) locally, by the looseness and the instability of the open-work active layer.

\subsection{Previous Studies and Monitoring Activity}

The Combe de Laurichard was chosen by Francou [24] for achieving different geomorphological studies of scree slopes dynamics. Among other activities, Francou originally marked more than 40 blocks, among which 15 have been regularly measured since 1984 up to present (yearly since 1999, every $1-3$ years before). Initially, blocks were positioned using a tacheometer [21], then a total station was used from 1992-2013, and since 2012, a differential dual-frequency GPS has been used in real-time kinematic (RTK) mode. This still ongoing long-term survey has allowed quantifying the annual surface velocity of the Laurichard rock glacier along its main flow line for more than three decades $[25,26]$ with an overall centimetric accuracy.

Comparison between the 2005 TLS datasets and a digital elevation model (DEM) representing the topography in 1975 (from digitizing the 10-m contours of the 1:25,000 IGN topographic map) shows that a large part of the rock glacier movement occurs on its right-hand side [20]. To account for this specific pattern of the rock glacier flow, new marked blocks were therefore added in 2008 to the original network of points (Figure 1). 


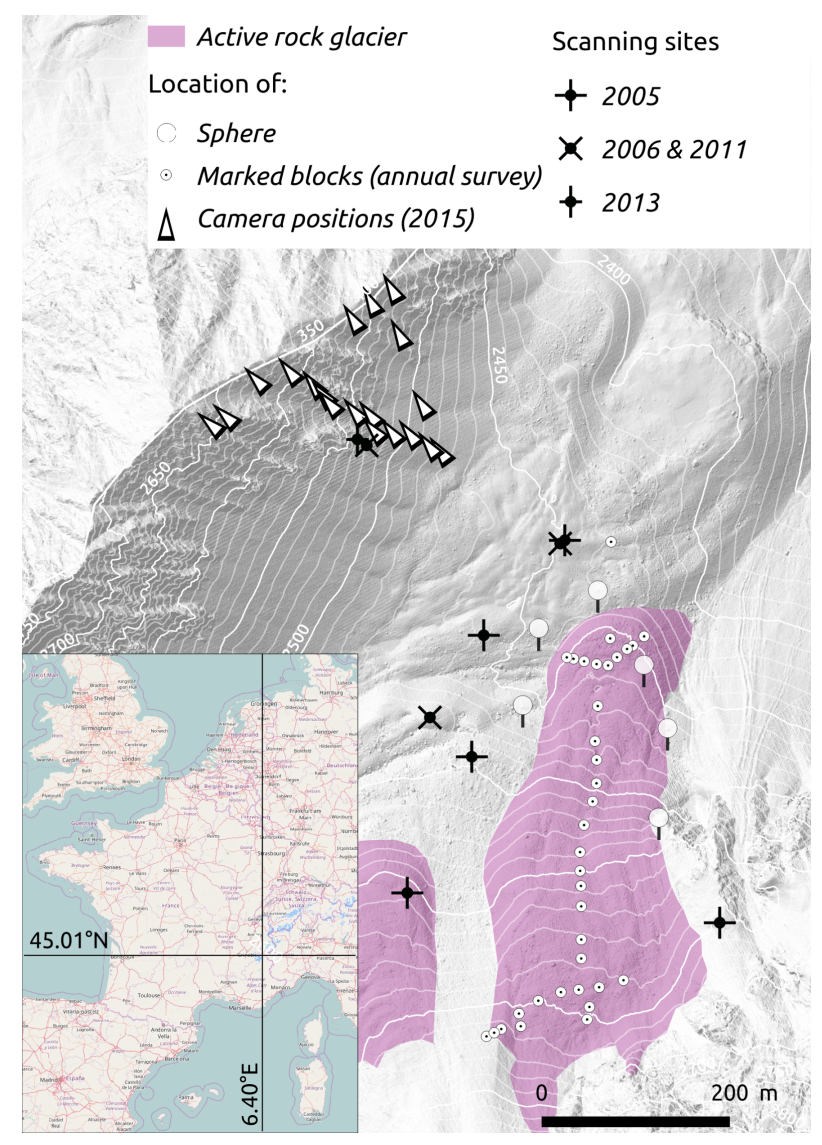

Figure 1. Map of the study area with the location of: (1) the targets (spheres with a diameter of $30 \mathrm{~cm}$, anchored on stable terrain) used for georeferencing; (2) the annually surveyed marked blocks (DGPS); and (3) the cameras for the 2015 survey (symbols are oriented with the optical axis of the lens). The lower-left inset shows the general location of the study area in the French Alps (source: Open Street Map).

\section{Data and Methods}

\subsection{Datasets Collection}

Since 2005, we conducted several measurement campaigns on the rock glacier aiming at generating DEMs that fulfill the following requirements: (i) a wide spatial coverage, at least the lower half of the rock glacier; (ii) a spatial resolution finer than the coarser blocks at the surface, the size of which is roughly estimated to be greater than $50 \mathrm{~cm}$; and (iii) a quality that will allow at least an annual inter-comparison of the DEMs.

For that purpose, we performed several TLS and SFM-MVS campaigns. We also benefited from an ALS survey performed in 2012. After post-processing the initial datasets (see the following section), six DEMs have been generated at a resolution ranging from $5 \mathrm{~cm}-50 \mathrm{~cm}$.

All DEMs were referenced in the RGF93 grid coordinate system based on the Lambert 93 conformal conic projection and the RAF09 geoid model for elevation reference (standard coordinate reference system of the French IGN, Institut National de l'Information Géographique et Forestière).

\subsubsection{TLS Datasets}

For the TLS surveys, we used an Optech ${ }^{\circledR}$ Ilris 3D scanner (Teledyne Optech,Vaughan, ON, Canada) (in 2005, 2006 and 2011) and an Optech ${ }^{\circledR}$ Ilris 3D-LR (long range) scanner (Teledyne Optech, Vaughan, ON, Canada) (in 2013). Details on the measurement capacities of the devices are described in Table 1. 
For each of the four TLS surveys, between one and three stations were used to minimize the areas not viewed by the laser.

Between 5 and 12 artificial (35 cm-diameter spheres fixed on stable and moving rocks) and/or natural targets were measured during each campaign, using dual-frequency GNSS receivers, in differential mode (DGPS), allowing a relative accuracy of a few centimeters.

Table 1. Technical overview of the terrestrial laser scanners used in the study (from the Optech ${ }^{\circledR}$ factsheets).

\begin{tabular}{ccc}
\hline & Ilris 3D & Ilris 3D-LR \\
\hline Range (80\% reflectivity) & $1200 \mathrm{~m}$ & $3000 \mathrm{~m}$ \\
Range (10\% reflectivity) & $400 \mathrm{~m}$ & $1300 \mathrm{~m}$ \\
Accuracy on distance & $7 \mathrm{~mm} @ 100 \mathrm{~m}$ & $7 \mathrm{~mm} \mathrm{@} 100 \mathrm{~m}$ \\
Angular accuracy & $80 \mu \mathrm{rad}$ & $80 \mu \mathrm{rad}$ \\
Position accuracy & $8 \mathrm{~mm} @ 100 \mathrm{~m}$ & $8 \mathrm{~mm} @ 100 \mathrm{~m}$ \\
Laser footprint & $29 \mathrm{~mm} @ 100 \mathrm{~m}$ & $27 \mathrm{~mm} @ 100 \mathrm{~m}$ \\
Laser beam divergence & $0.17 \mathrm{mrad}$ & $0.25 \mathrm{mrad}$ \\
Wavelength & $1500 \mathrm{~nm}$ & $1064 \mathrm{~nm}$ \\
Acquisition frequency & $2 \mathrm{kHz}$ & $10 \mathrm{kHz}$ \\
Field of view & $40^{\circ} \times 40^{\circ}$ & $40^{\circ} \times 40^{\circ}$ \\
\hline
\end{tabular}

\subsubsection{ALS Datasets}

The flight was performed by Sintégra ${ }^{\circledR}$ on 16 and 17 August 2012, with a Riegl LMS Q680i laser scanner on board a Cessna 206, flying at a nominal elevation above the ground of $610 \mathrm{~m}$. The sky was clear with limited wind ( $<10 \mathrm{kts})$. The point density after filtering was $7 \mathrm{pts} / \mathrm{m}^{2}$. The embedded dual-frequency GNSS and inertial motion unit, coupled with a GNSS base station allow a positional accuracy of $5 \mathrm{~cm}$ and an angular accuracy of $0.01^{\circ}$ of the laser scanner position at each time during the flight.

Sintégra performed the post-processing (point cloud modeling, filtering, DEM generation and orientation), as well as the evaluation of the dataset by comparing to in situ GNSS measurements (45 points on a flat artificial surface, yielding a vertical accuracy (RMSE) of the 3D point cloud within $2 \mathrm{~cm})[27]$.

\subsubsection{SFM-MVS Datasets}

On 16 September 2015, 27 pictures were taken from the Pyramide de Laurichard, i.e., facing the rock glacier (cf. Figure 1), with a Nikon D800 reflex camera, equipped with a 35-mm fixed-focal lens. The weather was cloudy, with mostly diffuse solar radiation, allowing a rather constant lighting of the terrain and homogeneous white balance distribution during the survey.

The initial raw (.nef Nikon file format) images were converted to .tiff format using XN Converter freeware. The images were processed in the commercial Photoscan Agisoft ${ }^{\circledR}$ software, with the following procedure: (1) selection of images using a quality index (7 images removed); (2) camera alignment and markers retrieval; (3) dense cloud processing; (4) export DEM at a 10-cm pixel resolution. Georeferencing of the 3D model is based on DGPS measurements of the artificial targets (spheres) and additional natural targets (blocks) visually detected on the 2012 ALS-derived DEM.

\subsection{Datasets Processing}

\subsubsection{Co-Registration of the DEMs}

Once each DEM had been individually georeferenced, they were all co-registered on stable areas with the 2005 DEM used as a reference. This was performed using a standard best-fit alignment procedure in InnovMetric ${ }^{\circledR}$ Polyworks software (InnovMetric Software Inc., Quebec, QC, Canada), 
which minimizes by a least-square method the distance between the two 3D models. The accuracy of the co-registration is assessed by the statistics of the error distribution (Table 2).

Table 2. Accuracy of the datasets, with absolute values based on the manufacturer factsheet (TLS) or software processing results (SFM-MVS with Agisoft Photoscan), and relative values based on the co-registration error of each DEM on 2005 DEM. * Data according to the manufacturer factsheets.

\begin{tabular}{|c|c|c|c|c|c|c|}
\hline & 2005 & 2006 & 2011 & 2012 & 2013 & 2015 \\
\hline Type of survey & TLS & TLS & TLS & ALS & TLS & SFM-MVS \\
\hline Date of survey & 18 September & 25 August & 13 September & 16/17 August & 10 October & 16 September \\
\hline Sensor & Ilris-3D & Ilris-3D & Ilris-3D & Rieg1 LMS Q680i & Ilris-3D LR & Nikon D800 \\
\hline Position accuracy * & 8 mm@100 m & 8 mm@100m & 8 mm@100m & 20 mm @ 250 m & 7 mm@100 m & $68 \mathrm{~mm}$ (6 GCPs) \\
\hline $\begin{array}{l}\text { Co-registration } \\
\text { error on } 2005 \text { point } \\
\text { cloud: mean }(\mathrm{m})\end{array}$ & - & 0.102 & 0.030 & 0.003 & -0.053 & 0.144 \\
\hline $\begin{array}{l}\text { Co-registration } \\
\text { error on } 2005 \text { point } \\
\text { cloud: SD }(\mathrm{m})\end{array}$ & - & 0.301 & 0.289 & 0.513 & 0.213 & 0.148 \\
\hline $\begin{array}{l}\text { Number of } \\
\text { non-NApoints } \\
\text { compared }\end{array}$ & - & 332,831 & 287,860 & 14,029 & 100,992 & 903,269 \\
\hline
\end{tabular}

\subsubsection{Image Correlation for Surface Displacement Measurement}

In order to compute 3D displacements of the rock glacier between each pair of DEMs (2006-2005, 2011-2006, 2012-2011 and 2015-2012; note that the 2013 DEM appeared as too noisy and unfavorable for image correlation), the elevation grids were processed in the IMCORRmodule within SAGA-GIS [28,29]. The algorithm retrieves pixels pattern between two georeferenced images and produces shapefiles (points and lines) containing the 2D and 3D displacements. Three parameters can be set: the search chip size, the pattern size and the grid sampling interval.

All the original DEMs were resampled at a 10-cm resolution and set in a common $2201 \times 2951$ pixels grid system. Several parameter combinations were tested, the best scores being achieved for the following parameter values: search chip: 64 or 128 pixels; pattern: 16 or 32 pixels; grid interval: 3 or 4 .

The surface displacement datasets were manually cleaned due to border effects between grids with different local spatial coverage and artifacts (e.g., related to random local similarity of the coarse blocky surface) and then exported into a point-shapefile. This latter dataset was then interpolated (inverse distance weighting method, with a search radius of $10 \mathrm{~m}$ and a Gaussian weighting) into a 2-m resolution grid.

\subsubsection{Comparison of Computed Surface Displacements with Ground-Based Measurements}

As mentioned previously, 35 blocks located along three lines crossing the rock glacier (Figure 1) have been annually measured by the Parc national des Ecrins since 1999 [25]. Interannual displacements are therefore available for those points and can be compared, in the three dimensions, to the surface displacements (distance and direction) computed from images' correlation.

\section{Results}

\subsection{Evaluation of the Vertical Accuracy}

To assess the vertical accuracy of the datasets, we performed a pixel-to-pixel difference of the successive pairs of DEMs on stable areas (Table 3). For the 600-800 thousands points compared, the absolute maximal elevation difference is below $2.5 \mathrm{~m}$, with a standard-deviation (SD) and a root-mean-squared error (RMS) within 15 and $27 \mathrm{~cm}$. As expected, the distribution of the DEMs' difference is centered (the average equals zero), except for the 2015-2013 DEMs comparison, for which 
the 2015 model is locally suffering from broad-scale disturbances probably due to an uncorrected radial distortion inherent to an insufficient calibration in the SFM-MVS process [30].

Table 3. Vertical differences (in meters) between successive pairs of DEMs in stable areas around the rock glacier (sub-vertical rock face, flat Quaternary moraine and gently inclined fossil rock glacier).

\begin{tabular}{cccccc}
\hline & 2006-2005 & 2011-2006 & 2012-2011 & 2013-2012 & 2015-2013 \\
\hline Min & -2.43 & -2.4 & -2.47 & -2.02 & -1.82 \\
Max & 2.1 & 2.29 & 2.48 & 1.4 & 2.27 \\
Median & 0.03 & -0.03 & -0.00 & 0.03 & 0.19 \\
Mean & 0.03 & -0.01 & -0.04 & 0.04 & 0.18 \\
SD & 0.25 & 0.21 & 0.23 & 0.14 & 0.20 \\
RMSE & 0.25 & 0.21 & 0.24 & 0.15 & 0.27 \\
non-NA & 732,000 & 766,023 & 832,995 & 642,490 & 635,736 \\
\hline
\end{tabular}

\subsection{Evaluation of the Displacement Quantification}

A preliminary visual inspection of the shaded-relief DTMs made from the 10-cm $(2005,2006,2011$, 2013, 2015) and 50-cm (2012) DEMs (cf. Supplementary Material) clearly shows the coherent patterns of the rock glacier deformation: stable areas outside the rock glacier, main central flow line along the maximal slope with reduced displacements towards the sides, higher velocity in the steepest upper part of the rock glacier and a bend of the movement towards its right orographic side.

Mapping the surface displacements derived from image correlation and from ground measurements shows a good agreement between the two approaches (Figure 2). The direction of the vectors is satisfactorily reproduced, as well as the their amplitude with an RMS error of $0.16 \mathrm{~m} / \mathrm{yr}$ (Figure 3).

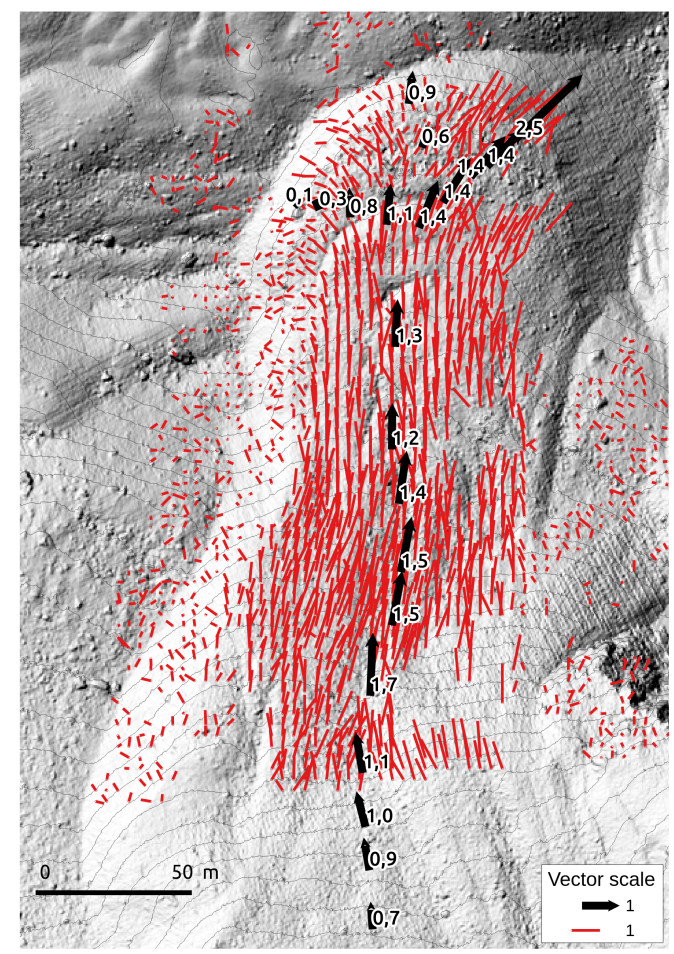

Figure 2. Surface velocity (m/yr) on the Laurichard rock glacier for the period 2011-2012 quantified by image correlation on DEMs (red lines) and by ground topographic (total station and DGPS) measurements of marked blocks (black arrows). 


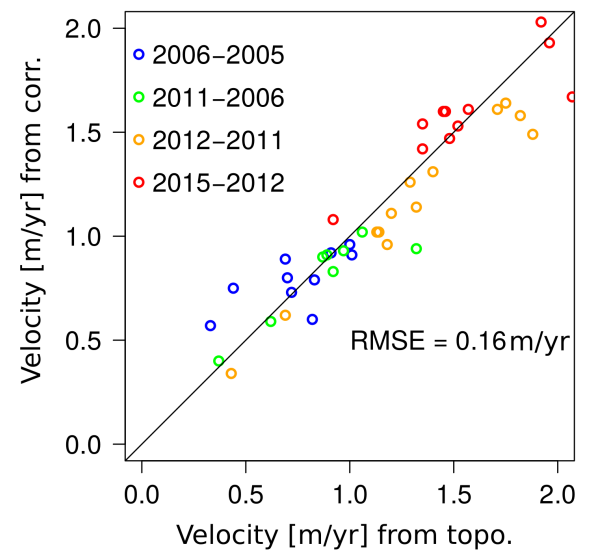

Figure 3. Surface velocity derived from image correlation (computed from the values of the 10 closest points around the actual position of the marked blocks) versus 3D surface velocity measured on marked blocks.

\section{Interpretation of the Results}

\subsection{Spatio-Temporal Variation of the Rock Glacier Velocity}

Though varying in amplitude, the spatial distribution of the movement remained rather homogeneous in space, with a very fast zone $(>1 \mathrm{dm} / \mathrm{yr})$ in the upper surveyed area and a very slow area (a few $\mathrm{m} / \mathrm{yr}$ or less) on the left flank of the tongue (Figure 4). The orographic-right bend is also visible at every period, as well as marked border effects with a clear velocity lowering from the center flow line to the lateral sides. A localized lack of displacement vectors on the 2006-2011 datasets is due to a shallow dry debris-flow that took place over the steepest part of the rock glacier. This drastic morphological change, visible on the shaded-relief DTMs, impeded pattern retrieval by the image correlation algorithm.
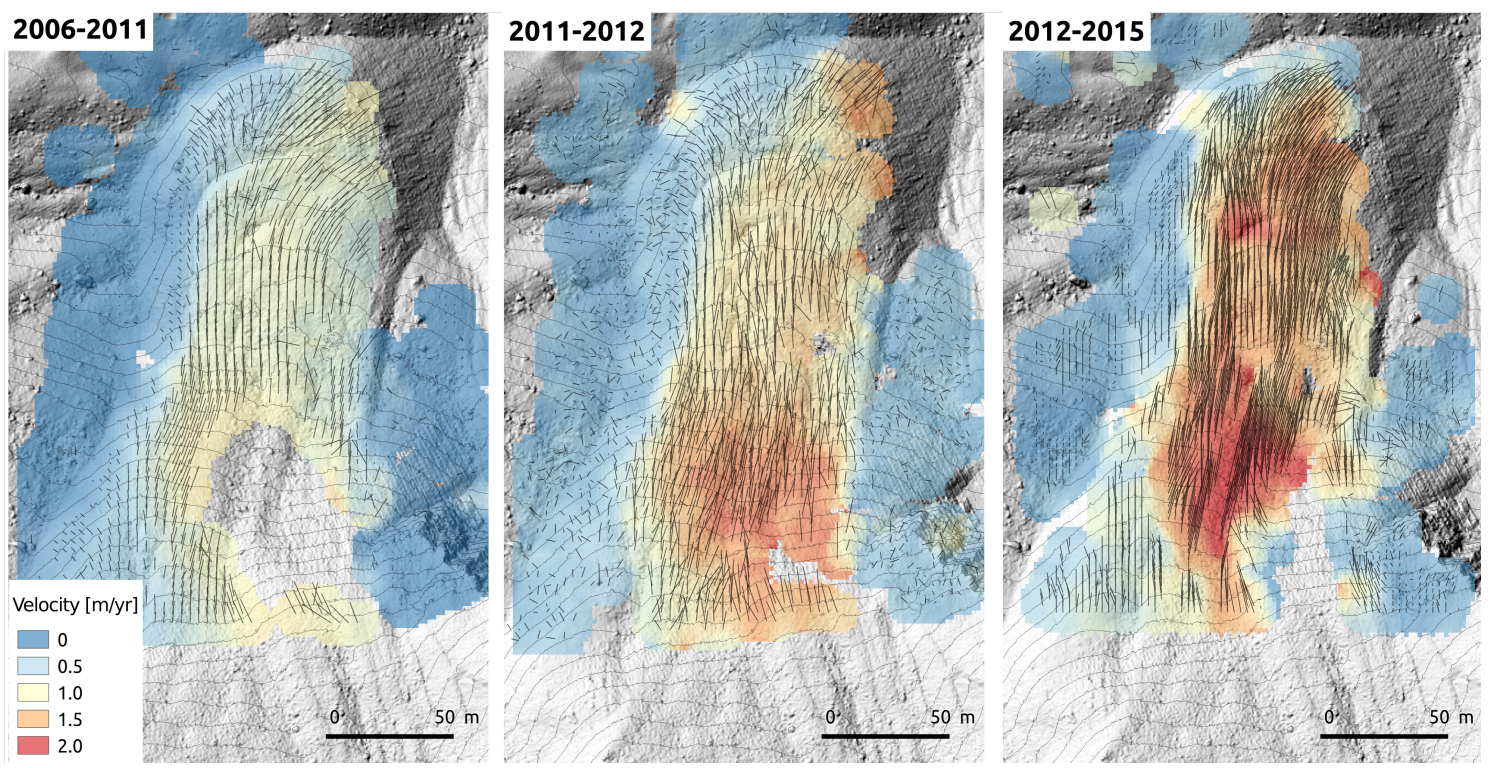

Figure 4. Maps of the surface velocity of the Laurichard rock glacier at three different time periods, as derived from image correlation using HR DEMs. 
The mean ground-measured velocity (bold dashed line in Figure 5) and the velocity fields computed from image correlation over the whole rock glacier surface (red bold line in Figure 5) both display a close mean value, suggesting that the design of the annual topographic survey is well representative of the average rock glacier movement. Deviations of $\pm 5-15 \%$ are also observable between both curves. Though this is within the error range of the velocity derived from image correlation, it can nevertheless be assumed that this could come from the heterogeneous velocity patterns: temporary acceleration or deceleration of specific areas of the rock glacier would be captured by the glacier-wide measurements derived from DEM correlation, but not by the network of blocks surveyed. The spread (standard deviation) of the image correlation-derived values also shows the overall large spatial variability of the velocity, especially changing between the rapid central flow line and the slower sides.

The longitudinal velocity profile (Figure 6) shows a generalized progressive increase in the surface displacements, between 2005-2006 and 2012-2015. The mean velocity along the profile changed from $0.82-1.80 \mathrm{~m} / \mathrm{yr}$, which corresponds to a $45 \%$ increase over the entire period (respectively 6,27 and 21\% for 2005-2006/2006-2011, 2006-2011/2011-2012, 2011-2012/2012-2015). This acceleration is not homogeneously distributed along the profile and varies through time: it remained almost constant (around 40-50\%) along the steepest part (horizontal distance: from 50-150 m, with partial data gaps of 25 and $80 \mathrm{~m}$ ). On the lowest part (horizontal distance: above $150 \mathrm{~m}$ ), the velocity remained rather constant (interannual velocity variation roughly ranging from $30--30 \%$ ) over the first two periods (2005-2006/2006-2011, 2006-2011/2011-2012), whereas it clearly increased between 2011-2012 and 2012-2015.

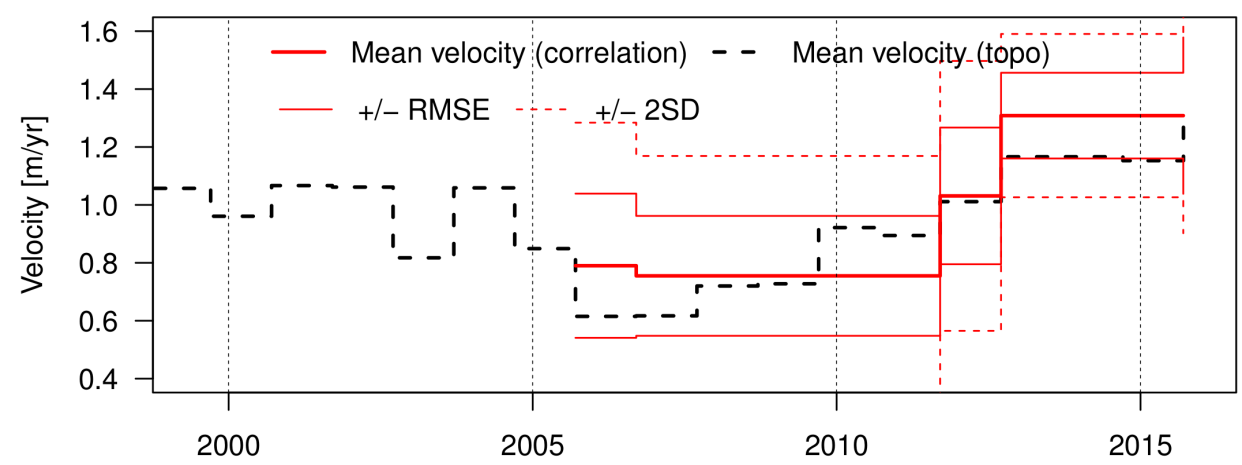

Figure 5. Evolution of the Laurichard rock glacier mean velocity since the early 2000s, derived from ground topographic measurements (total station and DGPS; bold black dashed line) and from image (DEM) correlation (red lines).

\subsection{Deformation Patterns}

The deformation pattern is here quantified by the relative spatial variation of velocity along the longitudinal profile (Figure 7), which mostly allows one to identify the compressive and extensive sectors along the profile. A compression area is visible near the front (horizontal distance $>200 \mathrm{~m}$ ), due to the decrease in velocity just uphill of the front and the consequent buttressing effect. Higher up along the profile, a lateral shift of the compressive-extensive zone seems also observable between the two periods considered in our measurements, amounting to approximately $10 \mathrm{~m}$, in coherence with the longitudinal translation of the ridges and furrows. Some significant changes, between the two periods, of the longitudinal velocity variation can be seen around 115 and $125 \mathrm{~m}(-20 \%)$ and around 130 and $140 \mathrm{~m}(+15 \%)$. 


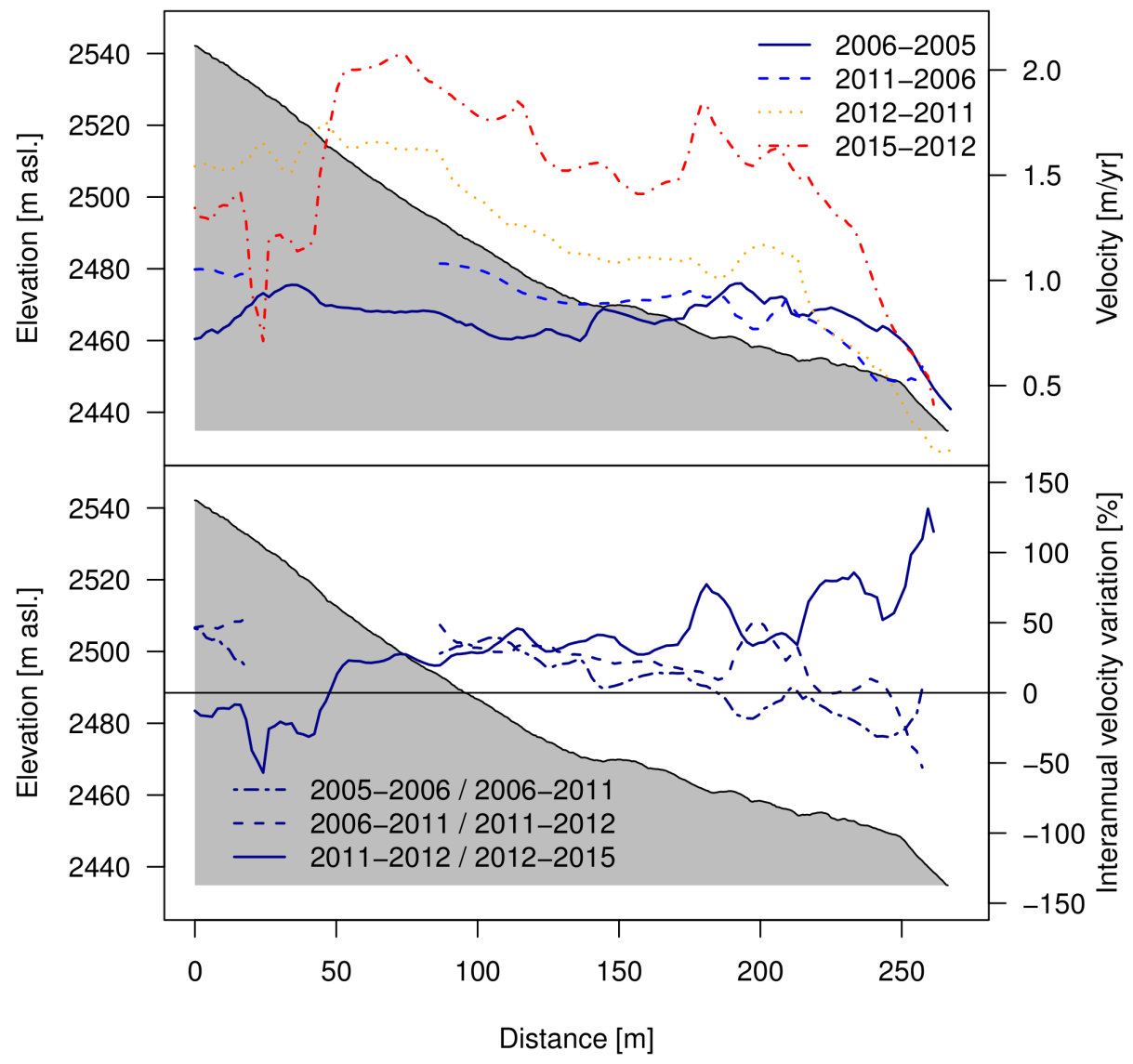

Figure 6. Variation of velocity along the longitudinal axis of the Laurichard rock glacier between 2005 and 2015, derived from image correlation. The upper panel shows the velocity profile for each period, and the lower panel depicts the variations of velocity between the different periods.

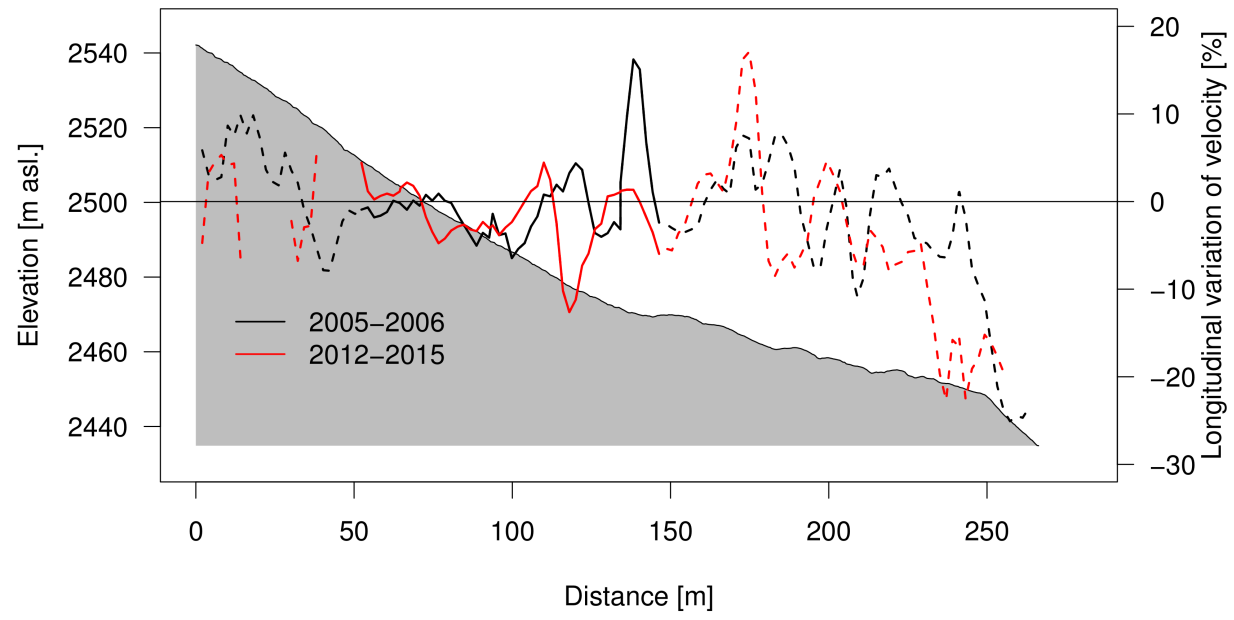

Figure 7. Relative spatial variation of velocity along the longitudinal axis of the Laurichard rock glacier for the slowest period (2005-2006, in black) and the fastest period (2012-2015, in red). Positive values indicate an increasing velocity towards downslope (extensive deformation), whereas negative values indicate a slowing down (compressive deformation). The plain line is used in the central section of the profile, which is referred to later on (see Figure 8). 


\section{Discussion}

\subsection{Representativeness of the Estimated Surface Velocity}

When statistically comparing the variability of the velocity measured from topographic surveys of marked blocks and the one of the velocity derived from image correlation of very high-resolution DEMs, we notice that: (i) the mean values of spatial variability from both methods are very close $(0.21 \mathrm{~m} / \mathrm{yr}$ for velocity derived from DEMs, $0.23 \mathrm{~m} / \mathrm{yr}$ for velocity derived from topographic surveys), which means that the network of blocks is well representative of the whole behavior of the rock glacier; (ii) the temporal variability is also quite similar; therefore, even if the time interval between DEMs can be longer than the annual time span between two topographic surveys, a similar temporal signal is captured by both methods; (iii) the non-stationarity of the two methods is well identified: the mean velocity derived from DEMs increases, as well as its variability.

\subsection{Topographic Control and Rheological Properties}

No clear control of slope (derived from the 2012 DEM resampled to $2 \mathrm{~m}$ ) on surface velocity can be detected when considering the entire profile (Figure 8). In order to account for the possible effect of surface roughness (many blocks are bigger than the 2-m DEM pixel size) and of the interannual variation of velocity, we also compared mean annual surface velocity measured with GPS between 2003 and 2016 with slopes derived from a 10-m DEM: similarly, no clear relationship appeared. Nevertheless, when considering only the 50-150-m section of the longitudinal profile (plain line section in Figure 7), a significant relationship is found for slope higher than $20^{\circ}$ (Figure 8 ). This specific pattern may be related to the specific rheological characteristics of the ice-debris mixture in a section of the profile that is mostly affected by creep, without acceleration and deceleration related to slope variation along the main flow line.

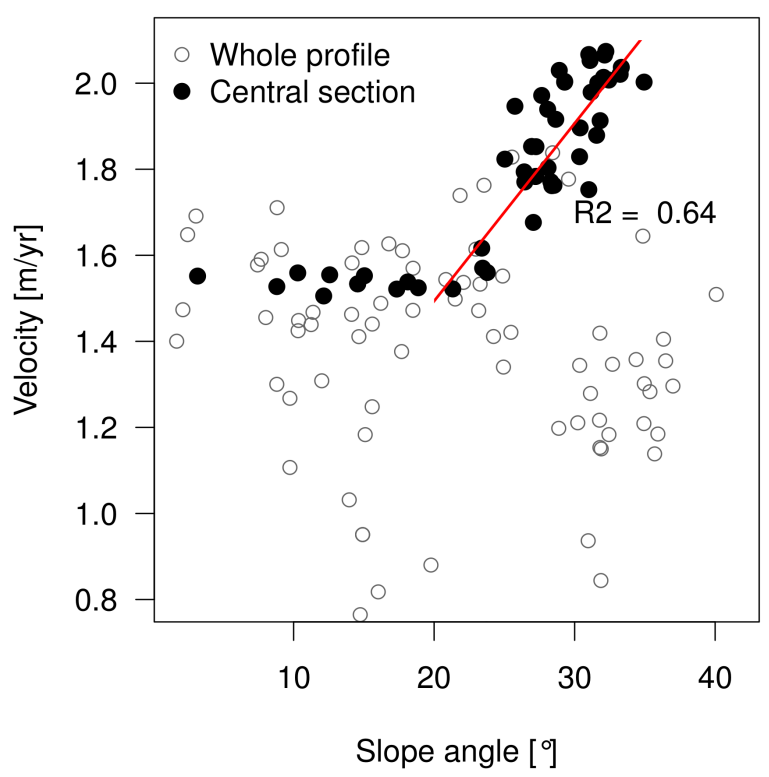

Figure 8. Velocity against slope along the longitudinal profile (circle), with values for the central section (horizontal distance between 50 and $150 \mathrm{~m}$; black dot). The red line is the regression fitted to the values for the central section for a slope angle above $20^{\circ}$.

\subsection{Limits and Perspectives of the Methods}

Very high resolution DEMs, obtained from laser scanning or photogrammetry, have already been used for rock glacier studies. For instance, [31] used multi-temporal LiDAR DEMs to derive velocity fields on a very fast rock glacier (surface velocities 2-7-times higher than the Laurichard case), 
whereas [32] compared TLS-derived DEMs to airborne orthophoto on a variety of moving landforms, including rock glaciers. Nevertheless, our study is the first to assess the accuracy of LiDAR- and SFM-MVS-derived DEMs for quantifying multi-temporal surface displacements of rock glacier with 'normal' velocities $(<2 \mathrm{~m} / \mathrm{yr})$.

We showed that interannual surface displacement fields of the Laurichard rock glacier can be derived in a rather straightforward way using high resolution DEMs. Though it is less precise than the geodetic survey of marked blocks, it is a complementary approach that allows describing precisely the spatial characteristics of the displacements. The combination of various sources of DEMs (terrestrial LiDAR, aerial LiDAR, SFM-MVS) is also possible, though it may complicate the selection of correct parameter values for the best retrieval of surface movement with the image correlation algorithm. One limit of this approach is the incomplete spatial coverage of terrestrial-based surveys, which leads to a lack of data in masked/hidden areas due to the limited view from the terrain. A good alternative could be, as proposed by [18], to use an unmanned aerial vehicle to produce a high resolution DEM that covers most of the study area.

\section{Conclusions}

By evaluating the very high resolution DEMs and surface displacement maps derived from those datasets, we can conclude that the various methods used to acquire the initial data (TSL, ALS, SFM-MVS) and the image correlation employed for further deriving displacement fields from DEMs are appropriate for investigating the multi-temporal kinematics of an active rock glacier. The accuracy we achieved for the DEMs, with horizontal and vertical errors around 0.15-0.3 $\mathrm{m}$ (excluding the ALS survey) and for the velocity fields (error of $0.16 \mathrm{~m} / \mathrm{yr}$ ), would also even allow one to quantify changes over a time interval shorter than a year, for instance to quantify displacement during summer. If both methods show similar spatial and temporal variability and are thus adapted for monitoring the pluri-annual velocity changes, temporary and localized changes in velocity, not captured by the topographic surveys of the blocks, may also occur as suggested by the differences between mean values derived from both methods. Therefore, in order to investigate the seasonal behavior of rock glaciers and to detect localized changes, we suggest to perform, every 1-3 years, TLS, ALS or terrestrial/drone SFM-MVS surveys in order to produce 10-50-cm DEMs, in addition to the annual topographic survey.

Supplementary Materials: The following are available online at www.mdpi.com/2072-4292/10/4/547/s1. The six 0.1-m pixel-size DEMs used in this study are available as Supplementary Material.

Acknowledgments: We acknowledge the Parc national des Ecrins for operating the topographic survey of the rock glacier since 1999. We are also grateful for the many people who helped in the field and for the SAJF (UMS 2925 CNRS/UGA), who provided us with the 50-cm ALS DEM and sometimes hosts us. The Ilris3D-LR laser scanner used in the study has been funded by the LabEx OSUG@2020 (Investissements d'avenir- ANR10 LABX56).

Author Contributions: X.B. coordinated the study, the data processing and interpretation and the writing of the manuscript. E.T. performed the comparison analysis of the spatial-temporal variability of both methods. O.S. processed the point clouds and performed the co-registration. A.R. helped in the TLS data acquisition, the interpretation of the results and edited the manuscript. S.J. helped with the acquisition and the processing of the TLS datasets.

Conflicts of Interest: The authors declare no conflict of interest. The founding sponsors had no role in the design of the study; in the collection, analyses or interpretation of data; in the writing of the manuscript; nor in the decision to publish the results.

\section{References}

1. Barsch, D. Rockglaciers. Indicators for the Present and Former Geoecology in High Mountain Environments; Number 16 in Springer Series in Physical Environment; Springer: Berlin/Heidelberg, Germany, 1996.

2. Haeberli, W.; Hallet, B.; Arenson, L.; Elconin, R.; Humlum, O.; Kääb, A.; Kaufmann, V.; Ladanyi, B.; Matsuoka, N.; Springman, S.; et al. Permafrost creep and rock glacier dynamics. Permafr. Periglac. Process. 2006, 17, 189-214. 
3. Delaloye, R.; Perruchoud, E.; Avian, M.; Kaufmann, V.; Bodin, X.; Hausmann, H.; Ikeda, A.; Kääb, A.; Kellerer-Pirklbauer, A.; Krainer, K.; et al. Recent interannual variations of rock glacier creep in the European Alps. In Proceedings of the 9th International Conference on Permafrost, Fairbanks, AK, USA, 29 June-3 July 2008; Volume 29, pp. 343-348.

4. Kellerer-Pirklbauer, A.; Bodin, X.; Delaloye, R.; Fischer, A.; Gärtner-Roer, I.; Hartl, L.; Kaufmann, V.; Krainer, K.; Lambiel, C.; Mair, V.; et al. Interannual variability of rock glacier surface velocities and its relationship to climatic conditions on a decadal scale: Some insights from the European Alps. In Proceedings of the EGU General Assembly Conference Abstracts, Vienna, Austria, 23-28 April 2017; Volume 19, p. 13912.

5. Roer, I.; Haeberli, W.; Avian, M.; Kaufmann, V.; Delaloye, R.; Lambiel, C.; Kääb, A. Observations and considerations on destabilizing active rock glaciers in the European Alps. In Proceedings of the Ninth International Conference on Permafrost, Fairbanks, AK, USA, 29 June 2008-3 July 2008; Institute of Northen Ingeneering, University of Alaska Fairanks: Fairbanks, AK, USA, 2008; Volume 2, pp. 1505-1510.

6. Bodin, X.; Krysiecki, J.M.; Schoeneich, P.; Le Roux, O.; Lorier, L.; Echelard, T.; Peyron, M.; Walpersdorf, A. The 2006 Collapse of the Bérard Rock Glacier (Southern French Alps). Permafr. Periglac. Process. 2016, 28, 209-223.

7. Bodin, X.; Krysiecki, J.M.; Iribarren Anacona, P. Recent collapse of rock glaciers: two study cases in the Alps and in the Andes. In Proceedings of the 12th Congress INTERPRAEVENT, Grenoble, France, 23-26 April 2012; pp. 2-3.

8. Krautblatter, M.; Leith, K. Glacier- and permafrost-related slope instabilities. In The High-Mountain Cryosphere; Huggel, C., Carey, M., Clague, J.J., Kaab, A., Eds.; Cambridge University Press: Cambridge, UK, 2015; pp. 147-165.

9. Kenner, R.; Phillips, M.; Beutel, J.; Limpach, P.; Papke, J.; Hasler, A.; Raetzo, H. Investigating the dynamics of a rock glacier using terrestrial laser scanning, time-lapse photography, in situ GPS measurements and satellite SAR inter-ferometry: Ritigraben rock glacier, Switzerland. In Proceedings of the International Conference on Permafrost, Potsdam, Germany, 20-24 June 2016.

10. Kääb, A.; Chiarle, M.; Raup, B.; Schneider, C. Climate change impacts on mountain glaciers and permafrost. Glob. Planet. Chang. 2007, 56, vii-ix.

11. Springman, S.M.; Arenson, L.U.; Yamamoto, Y.; Maurer, H.; Kos, A.; Buchli, T.; Derungs, G. Multidisciplinary investigations on three rock glaciers in the Swiss Alps: Legacies and future perspectives. Geogr. Ann. Ser. A Phys. Geogr. 2012, 94, 215-243.

12. Kenner, R.; Magnusson, J. Estimating the Effect of Different Influencing Factors on Rock Glacier Development in Two Regions in the Swiss Alps. Permafr. Periglac. Process. 2017, 28, 195-208.

13. Kääb, A.; Haeberli, W.; Gudmundsson, G.H. Analysing the creep of mountain permafrost using high precision aerial photogrammetry: 25 years of monitoring Gruben rock glacier, Swiss Alps. Permafr. Periglac. Process. 1997, 8, 409-426.

14. Arenson, L.U.; Kääb, A.; O'Sullivan, A. Detection and Analysis of Ground Deformation in Permafrost Environments: Ground Deformation in Permafrost Environments: Detection and Analysis. Permafr. Periglac. Process. 2016, 27, 339-351.

15. Lambiel, C.; Delaloye, R. Contribution of real-time kinematic GPS in the study of creeping mountain permafrost: examples from the Western Swiss Alps. Permafr. Periglac. Process. 2004, 15, 229-241.

16. Wirz, V.; Schirmer, M.; Gruber, S.; Lehning, M. Spatio-temporal measurements and analysis of snow depth in a rock face. Cryosphere 2011, 5, 893-905.

17. Piermattei, L.; Carturan, L.; de Blasi, F.; Tarolli, P.; Dalla Fontana, G.; Vettore, A.; Pfeifer, N. Suitability of ground-based SfM-MVS for monitoring glacial and periglacial processes. Earth Surf. Dyn. 2016, 4, 425-443.

18. Dall'Asta, E.; Forlani, G.; Roncella, R.; Santise, M.; Diotri, F.; Morra di Cella, U. Unmanned Aerial Systems and DSM matching for rock glacier monitoring. ISPRS J. Photogramm. Remote Sens. 2016, 127, 102-114.

19. Avian, M.; Bauer, A. First Results on Monitorin Glacier Dynamics with the Aid of Terrestrial Laser Scanning on Pasterze Glacier (Hohe Tauern, Austria). In Proceedings of the 8th International Symposium on High Mountain Remote Sensing Cartography, La Paz, Bolivia, 20-27 March 2005.

20. Bodin, X.; Schoeneich, P.; Jaillet, S. High-Resolution DEM Extraction from Terrestrial LIDAR Topometry and Surface Kinematics of the Creeping Alpine Permafrost: The Laurichard Rock Glacier Case Study (Southern French Alps). In Proceedings of the Ninth International Conference on Permafrost, Fairbanks, AK, USA, 29 June-3 July 2008; pp. 137-142. 
21. Francou, B.; Reynaud, L. 10 year surficial velocities on a rock glacier (Laurichard, French Alps). Permafr. Periglac. Process. 1992, 3, 209-213.

22. Durand, Y.; Laternser, M.; Giraud, G.; Etchevers, P.; Lesaffre, B.; Mérindol, L. Reanalysis of 44 Yr of Climate in the French Alps (1958-2002): Methodology, Model Validation, Climatology, and Trends for Air Temperature and Precipitation. J. Appl. Meteorol. Climatol. 2009, 48, 429-449.

23. Durand, Y.; Giraud, G.; Laternser, M.; Etchevers, P.; Mérindol, L.; Lesaffre, B. Reanalysis of 47 Years of Climate in the French Alps (1958-2005): Climatology and Trends for Snow Cover. J. Appl. Meteorol. Climatol. 2009, 48, 2487-2512.

24. Francou, B. Chutes de pierres et éboulisation dans les parois de l'étage périglaciaire. Revue de Géographie Alpine 1982, 70, 279-300.

25. Bodin, X.; Thibert, E.; Fabre, D.; Ribolini, A.; Schoeneich, P.; Francou, B.; Reynaud, L.; Fort, M. Two decades of responses (1986-2006) to climate by the Laurichard rock glacier, French Alps. Permafr. Periglac. Process. 2009, 20, 331-344.

26. Bodin, X.; Schoeneich, P.; Deline, P.; Ravanel, L.; Magnin, F.; Krysiecki, J.M.; Echelard, T. Mountain permafrost and associated geomorphological processes: recent changes in the French Alps. Revue de Géographie Alpine 2015, 103, doi:10.4000/rga.2885.

27. Méchin, C. Acquisition D'une Couverture Topographique par MéThode Laser. Rapport de Campagne LiDAR AéRoporté sur le Secteur du col du Lautaret pour l'Université Joseph Fourier; Technical Report 10330; Sintégra: Grenoble, France, 2012.

28. Conrad, O.; Bechtel, B.; Bock, M.; Dietrich, H.; Fischer, E.; Gerlitz, L.; Wehberg, J.; Wichmann, V.; Böhner, J. System for Automated Geoscientific Analyses (SAGA) v. 2.1.4. Geosci. Model Dev. Discuss. 2015, 8, 1991-2007.

29. Scambos, T.A.; Dutkiewicz, M.J.; Wilson, J.C.; Bindschadler, R.A. Application of image cross-correlation to the measurement of glacier velocity using satellite image data. Remote Sens. Environ. 1992, 42, 177-186.

30. James, M.R.; Robson, S. Sequential digital elevation models of active lava flows from ground-based stereo time-lapse imagery. ISPRS J. Photogramm. Remote Sens. 2014, 97, 160-170.

31. Buchli, T.; Kos, A.; Limpach, P.; Merz, K.; Zhou, X.; Springman, S.M. Kinematic investigations on the Furggwanghorn Rock Glacier, Switzerland. Permafr. Periglac. Process. 2018, 29, 1-18.

32. Kenner, R.; Bühler, Y.; Delaloye, R.; Ginzler, C.; Phillips, M. Monitoring of high alpine mass movements combining laser scanning with digital airborne photogrammetry. Geomorphology 2014, 206, 492-504.

(C) 2018 by the authors. Licensee MDPI, Basel, Switzerland. This article is an open access article distributed under the terms and conditions of the Creative Commons Attribution (CC BY) license (http://creativecommons.org/licenses/by/4.0/). 